\title{
1 Discovering genomic regions associated with the phenotypic 2 differentiation of European local pig breeds
}

Klavdija Poklukar ${ }^{1, a}$, Camille Mestre ${ }^{2, a}$, Martin Škrlepp ${ }^{1}$, Marjeta Čandek-Potokar ${ }^{1}$, Cristina Ovilo ${ }^{3}$, Luca Fontanesi ${ }^{4}$, Juliette Riquet ${ }^{2}$, Samuele Bovo ${ }^{4}$, Giuseppina Schiavo ${ }^{4}$, Anisa Ribani ${ }^{4}$, Maria Muñoz ${ }^{3}$, Maurizio Gallo ${ }^{5}$, Ricardo Bozzi ${ }^{6}$, Rui Charneca ${ }^{7}$, Raquel Quintanilla ${ }^{8}$, Goran Kušec ${ }^{9}$, Marie J. Mercat ${ }^{10}$, Christoph Zimmer ${ }^{11}$, Violeta Razmaite ${ }^{12}$, Jose P. Araujo ${ }^{13}$, Čedomir Radović ${ }^{14}$, Radomir Savić $^{15}$, Danijel Karolyi ${ }^{16}$, and Bertrand Servin ${ }^{2 *}$

${ }^{1}$ Agricultural Institute of Slovenia, Hacquetova ulica 17, 1000 Ljubljana, Slovenia

${ }^{2}$ GenPhySE, Université de Toulouse, INRAE, INP, ENVT, Castanet-Tolosan, 31320, France

${ }^{3}$ Departamento Mejora Genética Animal, INIA-CSIC, Crta. de la Coruña km. 7,5, 28040, Madrid, Spain

${ }^{4}$ Department of Agricultural and Food Sciences, Division of Animal Sciences, University of Bologna,

${ }^{5}$ Associazione Nazionale Allevatori Suini (ANAS), Via Nizza 53, 00198 Roma, Italy

${ }^{6}$ DAGRI - Animal Science Section, Università di Firenze, Via delle Cascine 5, 50144 Florence, Italy

${ }^{7}$ MED- Mediterranean Institute for Agriculture, Environment and Development, Universidade de

${ }^{8}$ Programa de Genética y Mejora Animal, IRTA, Torre Marimon, 08140 Caldes de Montbui, Barcelona, Spain

${ }^{9}$ Faculty of Agrobiotechnical Sciences, University of Osijek, Vladimira Preloga 1, Osijek 31000 ,

Croatia

${ }^{10}$ IFIP Institut du porc, La Motte au Vicomte, BP 35104, 35651 Le Rheu Cedex, France

${ }^{11}$ Bauerliche Erzeugergemeinschaft Schwäbisch Hall, Haller Str. 20, Wolpertshausen 74549,

${ }^{12}$ Animal Science Institute, Lithuanian University of Health Sciences, Baisogala 82317, Lithuania 
${ }^{13}$ Centro de Investigação de Montanha (CIMO), Instituto Politécnico de Viana do Castelo, Escola Superior Agrária, Refóios do Lima, 4990-706 Ponte de Lima, Portugal

${ }^{14}$ Department of Pig Breeding and Genetics, Institute for Animal Husbandry, Belgrade-Zemun 25, 10000 Zagreb, Croatia

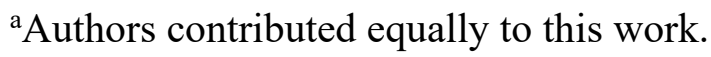

*Corresponding author

E-mail addresses:

KP: klavdija.poklukar@kis.si

CM: camille.mestre@inrae.fr or c.k.mestre@gmail.com

MŠ: martin.skrlep@,kis.si

MČP: meta.candek-potokar@kis.si

CO: ovilo@inia.es

LF: luca.fontanesi@unibo.it

JR: juliette.riquet@,inrae.fr

SB: samuele.bovo@unibo.it

GS: giuseppina.schiavo2@unibo.it

51 AR: anisa.ribani2@unibo.it

MM:mariamm@inia.es

MG: gallo@anas.it 
54 RB: riccardo.bozzi@unifi.it

55 RC: rmcc@uevora.pt

56 RQ: raquel.quintanilla@irta.cat

57 GK: gkusec@,fazos.hr

58 MJM: marie-jose.mercat@ifip.asso.fr

59 CZ: Christoph.Zimmer@,besh.de

60 VR: violeta.razmaite@1smuni.1t

61 JPA: pedropi@esa.ipvc.pt

62 ČR: cedomirradovic.izs@gmail.com

63 RS: savic@agrif.bg.ac.rs

64 DK: dkarolyi@agr.hr

65 BS: bertrand.servin@,inrae.fr 


\section{Abstract}

\section{Background}

Intensive selection of modern pig breeds resulted in genetic improvement of productive traits while local pig breeds remained less performant. As they have been bred in extensive systems, they have adapted to specifical environmental conditions resulting in a rich genotypic and phenotypic diversity. In this study, European local pig breeds were genotypically and phenotypically characterised using DNA-pool sequencing data and breed level phenotypes related to stature, fatness, growth and reproductive performance traits. These data were analysed using a dedicated approach to detect selection signatures linked to phenotypic traits in order to uncover potential candidate genes that may be under adaptation to specific environments.

\section{Results}

Genetic data analysis of European pig breeds revealed four main axes of genetic variation represented by Iberian and modern breeds (i.e. Large White, Landrace, and Duroc). In addition, breeds clustered according to their geographical origin, for example French Gascon and Basque breeds, Italian Apulo Calabrese and Casertana breeds, Spanish Iberian and Portuguese Alentejano breeds. Principal component analysis of phenotypic data distinguished between larger and leaner breeds with better growth potential and reproductive performance on one hand and breeds that were smaller, fatter, and had low growth and reproductive efficiency on the other hand. Linking selection signatures with phenotype identified 561 significant genomic regions. Among them, several regions contained candidate genes with possible biological effect on stature, fatness, growth and reproduction performance traits. For example, strong associations were found for stature in two regions containing $A N X A 4$ and $A N T X R 1$ genes, for growth performance containing TLL1 gene, for fatness containing $D N M T 3 A$ and $P O M C$ genes and for reproductive performance containing HSD17B7 gene. 
bioRxiv preprint doi: https://doi.org/10.1101/2022.02.22.481248; this version posted February 22,2022 . The copyright holder for this

preprint (which was not certified by peer review) is the author/funder, who has granted bioRxiv a license to display the preprint in perpetuity. It is made available under aCC-BY-ND 4.0 International license.

\section{Conclusions}

90 The present study on European local pig breeds used a newly developed approach for searching

91 selection signatures supported by phenotypic data at the breed level to identify potential candidate

92 genes that may have adapted to different living environments and production systems. Results can be

93 useful to define conservation programs of local pig breeds.

94 


\section{Background}

In the last decades, pig breeding has focused mainly on improving growth rate, carcass leanness, and reproductive performances (1) of relatively few breeds (2). On the other hand, the use of many local breeds has decreased while these breeds have not been subjected to such intensive management and genetic improvement. They are often raised in extensive farming systems, resulting in adaptation to specific environmental conditions and (usually) poor feeding resources (3). However, this adaptation to seasonal fluctuations in feed availability may have resulted in low productivity (4). As a result, many local pig breeds have been abandoned or have even become extinct, while most of them have faced population bottlenecks and genetic drifts or introgression from other pig populations $(5,6)$.

Today, many local breeds are used on a relatively limited scale and the available information on their phenotypic and genotypic traits is well known for only a few of them, such as Iberian or Meishan (7). Nonetheless, interest in local pig breeds has increased recently for several reasons, including their meat quality (allowing the production of high-quality meat products), their adaptation to local feeding resources, and society's awareness of phenotypic and genotypic biodiversity conservation (3). Being exposed to specific selection pressures in different local environments, local pig breeds also represent interesting genetic resources (8).

Recently, a genetic characterization of 20 European local pig breeds was carried out. It showed that some local breeds are clustered according to their geographical distribution (e.g. French Gascon and Basque breeds, Italian Apulo Calabrese and Casertana breeds, Spanish Iberian and Portuguese Alentejano breed), while some others suffer from introgressions or admixture with modern pig breeds (e.g. Lietuvos Baltosios Senojo Tipo and Lietuvos Vietiné with Large White and Landrace pigs; Mora Romagnola with Duroc pig) (8-10). Consequently, these breeds have developed particular heterogeneous phenotypic traits that could reflect specific genetic potential and adaptation to different 
production systems. As the measurement of phenotypic traits in pigs is to some extent standardised, it is possible to compare different local breeds. As shown in the study of Čandek-Potokar and Nieto (3) reviewing productive traits, the studied European local pig breeds not only differ from modern breeds, but are also quite variable and differ significantly among themselves.

To better understand the genetic basis for variation in phenotypic traits in local pig breeds, several genome-wide association studies focused on detecting possible associations of loci with different phenotypic attributes, such as morphological, production or meat quality traits (11-14). However, these studies worked with small number of samples, increasing the risk to give false negative results due to low statistical power (15). Another approach to search for the association between genetic polymorphisms and phenotype is to look for genomic regions that have responded to selection (i.e., selection signatures). Several studies in local breeds have shown that the signals detected contain gene variants/genes that may be associated with variations in phenotype, such as coat colour, growth, reproduction, or fatness $(8,9,16-19)$. The study by Muñoz et al. (9) determined the signatures of selection using SNP-array data in 20 European local breeds. This study revealed putative selection signals for regions containing genes involved in fatness, growth, reproduction, development, behaviour and sensory perception. A subsequent study, in which whole-genome sequencing was performed on DNA-pool samples from the same breeds/animals, detected several regions associated with coat colour, body size, growth, reproduction and fat deposition (8). In the aforementioned studies, the detected selection signatures did, however, not represent a direct association with a specific phenotype. Therefore, the present study proposes a different approach that attempts to determine selection signatures that are specifically linked to phenotype. It uses DNA-pool sequencing data from 19 European local and 3 modern pig breeds, as well as a database of many phenotypic traits in 20 local pig breeds associated with stature, fatness, growth and reproductive performance. The 
141

discovered genomic regions could reveal candidate genes with potential biological effects on specific phenotypic traits.

\section{Methods}

The aim of this study was to locate genomic regions associated with signatures of selection of local pig breeds for production traits. This was performed by combining genetic and phenotypic data at the breed (population) level. Most of the data used for this study have been previously published $(3,8,9)$. In this section, genetic and phenotypic datasets are presented, and then the methodological approach to detect signatures of selection on phenotypic traits is described.

\section{Genetic Datasets}

150 The present study was based on genetic data collected from 19 populations of local European pig 151 breeds and 7 populations of industrial breeds. The data consisted of SNP genotyping performed with 152 a medium density array (9) for 20 local breeds and whole genome sequencing of the pooled samples 153 (8) for 19 of them (the Iberian breed was not included). To better describe the genetic structure of the 154 local pig breeds, samples from additional 7 populations of 4 modern pig breeds were added but only 1553 of these samples were pool-sequenced. The final sample used for this study is shown in Table 1. 
Table 1. Name of pig breeds, country of origin and sample size.

\begin{tabular}{llll}
\hline Pig breed name & Country & $\begin{array}{l}\# \text { genotyped on SNP } \\
\text { array }\end{array}$ & $\begin{array}{l}\text { Sample } \\
\text { sequencing pool }\end{array}$ \\
\hline Local breeds & in \\
Alentejano & Portugal & 48 & 35 \\
Apulo Calabrese & Italy & 53 & 35 \\
Basque & France & 39 & 30 \\
Bísaro & Portugal & 48 & 35 \\
Black Slavonian & Croatia & 52 & 35 \\
Cinta Senese & Italy & 51 & 35 \\
Gascon & France & 48 & 30 \\
Iberian & Spain & 48 & - \\
Krškopolje & Slovenia & 52 & 35 \\
Lietuvos Baltosios Senojo Tipo & Lithuania & 48 & 35 \\
Lietuvos Vietiné & Lithuania & 48 & 35 \\
Mangalitsa & Serbia & 50 & 35 \\
Mora Romagnola & Italy & 48 & 35 \\
Moravka & Serbia & 49 & 35 \\
Negre Mallorquí & Spain & 48 & 35 \\
Nero Casertano & Italy & 53 & 35 \\
Nero Siciliano & Italy & 48 & 35 \\
Sarda & Italy & 48 & 35 \\
Schwäbisch-Hällisches & Germany & 49 & 35 \\
Turopolje & Croatia & 49 & 35 \\
Modern breeds & & & \\
Italian Large White & Italy & 4 & 35 \\
Large White & France & 97 & - \\
Italian Duroc & Italy & 5 & 35 \\
Duroc & France & 33 & - \\
Italian Landrace & Italy & 4 & 35 \\
Landrace & France & 53 & - \\
Pietrain & France & 61 & \\
\hline & & & \\
& & 48 & \\
\hline
\end{tabular}

\section{Quality control of genetic datasets}

160 For the SNP array data, quality control of SNP genotypes was performed for the entire dataset using

161 standard filters: only autosomal SNPs with $<10 \%$ missing data were retained. Following this step,

16210 individuals with $>3 \%$ missing genotypes were clear outliers in the sample and were therefore

163 discarded. 
Two analyses were performed for the pooled sequence data: estimation of SNP allele frequencies for variants in the SNP array and de novo variant discovery. De novo SNV discovery was carried out using CRISP (20) with default parameters and yielded 34,751,691 variants. From these, we filtered out variants with more than two alleles, variants with very low allele frequency that most likely resulted from sequencing errors (field $\mathrm{VP}=0$ and $\mathrm{AF}=1$ ), and variants with low mapping quality (QUAL < 1000, MQ < 20). After filtering, 16,403,270 SNPs were kept.

\section{Genetic structure of pig populations}

The genetic structure of pig populations was assessed from individual SNP genotyping data using PCA, admixture analysis (21) and population tree reconstruction with hapFLK. Admixture analysis was performed for a number of clusters $(\mathrm{K})$ between 2 to 40 to determine a value of $\mathrm{K}$ that best explained the data. The decrease in cross-validation error was monotonous from 2 to 40 (Additional File 1: Figure S1), but showed a diminishing decrease after $\mathrm{K}=24$, therefore this value was used as a reference to describe the genetic structure of the breeds. Based on the admixture results, individuals showing more than $80 \%$ of their genome assigned to the main cluster of their assigned breed were selected for inclusion in the population tree analysis. The Nero Siciliano breed did not show any individual matching to this criterion and was, therefore, not included in the population tree reconstruction.

To verify the quality of the pool sequence data, a comparison with the SNP array genotyping results was conducted. Allele frequencies of SNP array variants in the pooled sequence data were estimated using allele counts extracted with Samtools mpileup (22) and PoPoolation2 (23). Samtools was run with options -C 50 -q 20 (variants with mapping quality less than 20 were discarded as recommended by the software documentation). PoPoolation 2 was run with default parameters on the resulting mpileup file. From the resulting pool allele counts, allele frequencies and Fst for each pair of 
populations were then calculated using the approach of (24) implemented in the R package poolfstat. The population tree was constructed applying the neighbour-joining algorithm on the Fst matrix using the same procedure that was used on allele frequencies derived from the SNP array genotypes. PCA was performed on the pool-seq SNPs extracted from the SNP-chip data and showed high correlation across breeds (Additional File 1: Figure S2).

\section{Phenotypic characterization of local pig populations}

A database of phenotypic traits of European local pig populations was used to determine global breed differences in phenotype (3). Phenotypic variables were combined into four distinct groups summarizing stature, fatness, growth, and reproductive performance. The growth performance group included traits of average daily gain in 3 different growth periods (i.e. from lactation to early fattening phase; up to approximately $60 \mathrm{~kg}$ ). The stature group included traits of body weight and height of adult male and female animals. The fatness group comprised backfat thicknesses at different anatomical locations, fatty acid composition, carcass lean meat content and intramuscular fat content. To standardize the value of backfat thickness at the level of the last rib, an adjustment was made to the final body weight of $120 \mathrm{~kg}$ (see Additional file 2 for a more detailed description). The adjusted values were included in the PCA. The reproductive performance group included traits related to number of piglets per litter, number of litters per year, piglets/litter weights, duration of lactation and farrowing interval. A more detailed description of the traits included in the phenotypic characterization can be found in Additional File 3: Table S1.

All statistical analyses were performed using R statistical software. Means for each variable and each breed were calculated and scaled. Since the phenotypic database was composed of results from different studies, some variables were missing for some breeds (Additional File 1: Figure S3). Missing data were imputed using regularized iterative PCA method using R package missMDA (25). 
Principal component analyses were performed using the R package FactoMiner (26) for the growth performance, reproductive performance, stature and fatness traits. Uncertainty in the predictions of missing data was assessed by multiple imputation (MIPCA function (27)). Breed loadings on the PC1 of each PCA were used as "breed scores" for the analysis of selection signatures.

\section{Genome scan for selection on phenotypic breed scores}

To identify genomic regions associated to selection on breed level phenotypes, we built upon the approach of (28) which we briefly describe here. Assuming data on allele frequencies measured in $\mathrm{r}$ populations at $\mathrm{L}$ loci, this association model at a locus 1 is:

$$
p^{l} \sim N\left(1 p_{0}^{l}+x \beta^{l}, V p_{0}^{l}\left(1-p_{0}^{l}\right)\right)
$$

where $p^{l}$ is the vector of allele frequencies in the $\mathrm{r}$ populations, $p_{0}^{l}$ is the (unknown) ancestral allele frequency of the locus, $x$ is the vector of breed level phenotypes, $\beta^{l}$ is the effect of phenotype on allele frequencies differences, and $V$ is the genome-wide variance-covariance matrix of allele frequencies between populations. The idea behind this model is that the adaptation of populations to covariate $x$ (here the breed level phenotypes) will drive allele frequency differences between populations away from their expectation under genetic drift. In (1), this expectation is modelled with the genome-wide covariance matrix V (see (28) for the detailed description). To perform statistical inference under this model the parameters $\mathrm{V}, \beta^{l}$ and $p_{0}^{l}$ need to be estimated. Under the null hypothesis (selection associated with phenotype $\mathrm{x}$ has not affected allele frequencies), the parameter $\beta^{l}$ is set to 0 . To test for association with the covariate $\mathrm{x},(28)$ use a MCMC algorithm allowing to derive a statistic for association (a Bayes Factor). This was later extended by (29) to account for uncertainty in allele frequency estimation in pool sequencing experiments. This approach was tested on our dataset, but was found computationally inefficient due to the very high number of SNPs considered. We therefore used a frequentist treatment of the model that consists in maximizing the 
likelihood of model (1) under the null and the alternative hypothesis and performing a likelihood ratio test. One deviation from this approach is that we account for the variation in sequencing depth in different pools by using regularized allele frequencies $p_{r}^{l}$ (see below) rather than fitting the model on the usual allele frequency estimates $\hat{p}_{r}^{l}$. The maximum likelihood estimator of allele frequencies is $\hat{p}_{r}^{l}=\frac{c_{r}^{l}}{n_{r}^{l}}$, where $c_{r}^{l}$ is the number of alternative allele counts and $n_{r}^{l}$ the sequencing depth for population $\mathrm{r}$ at locus 1 . This estimator has good properties provided the sequencing depth $n_{r}^{l}$ at the locus is large. However, this depth is highly variable along the genome and can be quite low (even 0) in some genomic regions. Moreover, it will vary between populations at a given locus. To regularize allele frequencies estimates, we used shrank allele frequencies estimates in the form:

$$
p_{r}^{l}=\frac{a^{l}+c_{r}^{l}}{b^{l}+n_{r}^{l}}
$$

where $a^{l}$ and $b^{l}$ are regularizing (prior) parameters set so that $a^{l} / b^{l}$ equals the alternative allele frequency among all populations at locus 1 . Doing so, if a population has no observed data at a SNP, its allele frequency will be similar to other populations which reduces the risk of false positives due to uneven sequencing coverage.

The association of breed scores to allele frequencies was tested for all SNPs for all breed scores (stature, growth performance, fatness traits, reproductive performance). The result of the test was a p-value for each SNP for each phenotypic trait. Since model (1) is only valid for intermediate ancestral allele frequencies, only SNPs where the ancestral allele frequency estimate $p_{0}^{l}$ lied between 0.05 and 0.95 were considered in the following. Statistical significance was established by estimating False Discovery Rates (FDR) with the approach of (30) using the qualue R package. The FDR 
threshold for detecting significant associations was set at $1 \%$. The number of significant variants with corresponding q-values for all phenotypic groups can be found in Additional File 3: Table S2.

Based on association statistics for individual SNP, we defined association regions by assuming that two SNPs belonged to the same region if they were less than $200 \mathrm{~kb}$ apart. For each significant region, candidate genes were extracted from the annotation of the reference genome (Sscrofa11.1). We chose to focus on the top 20 significant regions of each phenotypic group (i.e. those with the lowest P-value and with at least 3 significant SNPs) and genes within these regions were reviewed in the literature for potential biological effects on phenotypic differentiation. The top 20 significant regions for each phenotypic trait were summarized using the R package circlize (31). The allele frequencies of each breed at each SNP were extracted and plotted to highlight which breed most likely adapted for specific phenotypic traits.

\section{Results}

\section{Genetic structure of European pig breeds}

To characterize the genetic structure of populations, the individual genotypes on the SNP array were used to perform a standard genetic structure analysis. PCA analyses of 24 breeds revealed four main genetic backgrounds in the dataset (i.e. Iberian, Duroc/Mora Romagnola, Large White and Landrace/Pietrain backgrounds), visible in the first 3 principal components (Figure 1). PC1 and PC2 clearly distinguish between the Iberian pig, White pigs (Landrace, Large White and Pietrain) and Duroc/Mora Romagnola backgrounds. PC3 shows that the White pigs' background separates into a Large White specific background and a Landrace/Pietrain background. PC4 further separates the Turopolje breed from the Iberian group. The global pattern of differentiation between breeds in our dataset is thus strongly influenced by modern pig breeds. Local pig breeds are usually in intermediate positions, mostly within a triangle with summits corresponding to the Iberian breed, the 

were performed.
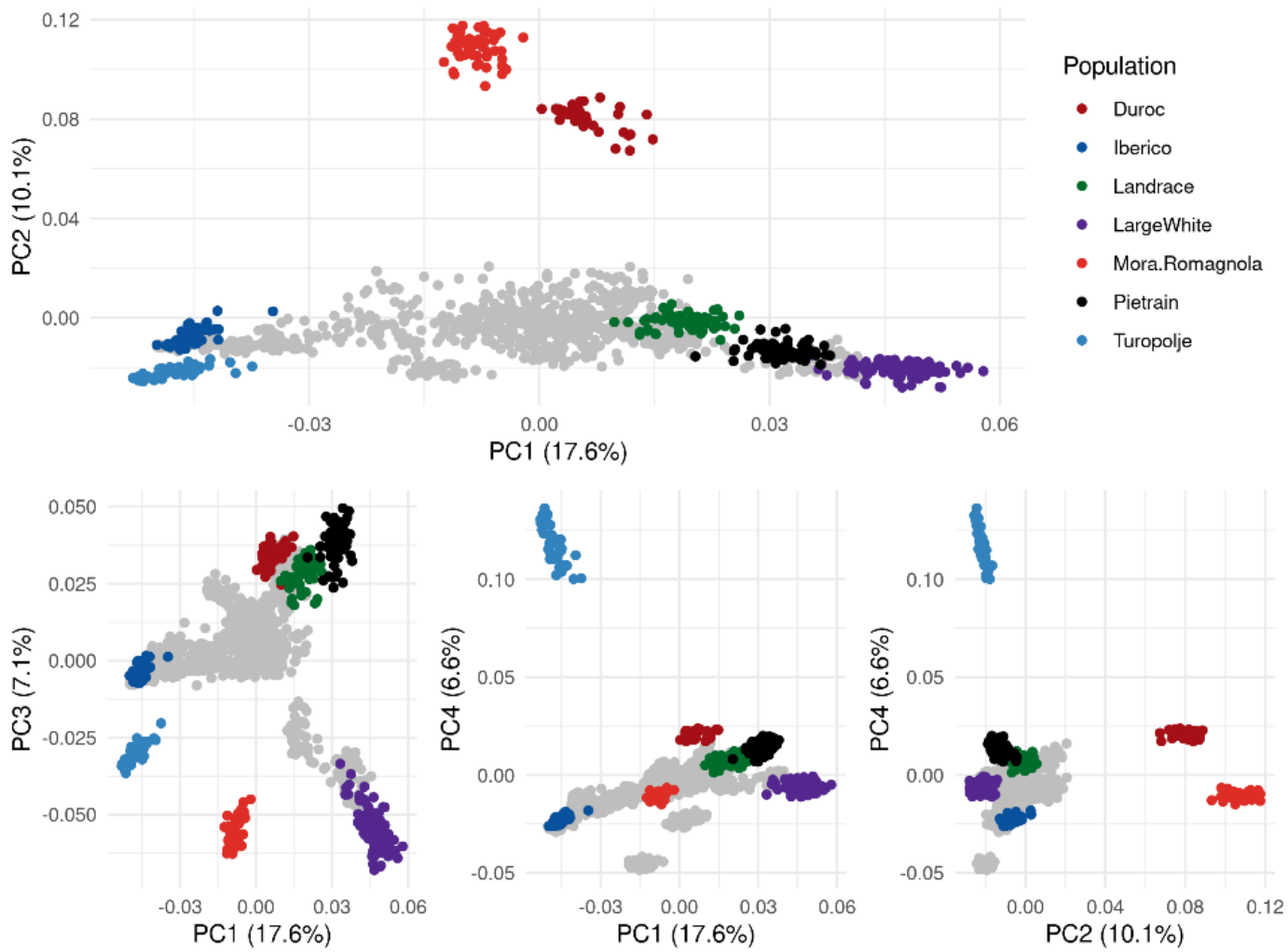

Figure 1. Principal component analysis of 24 pig breeds genotyped on a medium density SNP array. The most differentiated breeds are highlighted with different colours.

The results of the admixture analysis results show that the number of homogeneous clusters in the dataset is difficult to determine. The cross-validation procedure was conducted for up to 40 clusters and resulted in a general decrease in cross-validation error with increasing number of clusters (Additional File 1: Figure S1). However, the decrease slowed down after $\mathrm{K}=24$ clusters, a number that corresponds to the number of named breeds (Table 1). The further decrease is due to the fact that some breeds are sub-structured and require additional clusters to be well fitted. In the following, we present the results obtained with $\mathrm{K}=24$ corresponding to the inflexion point in the cross-validation 
curve. Figure 2 shows side-by-side the result of the population tree reconstruction and the admixture

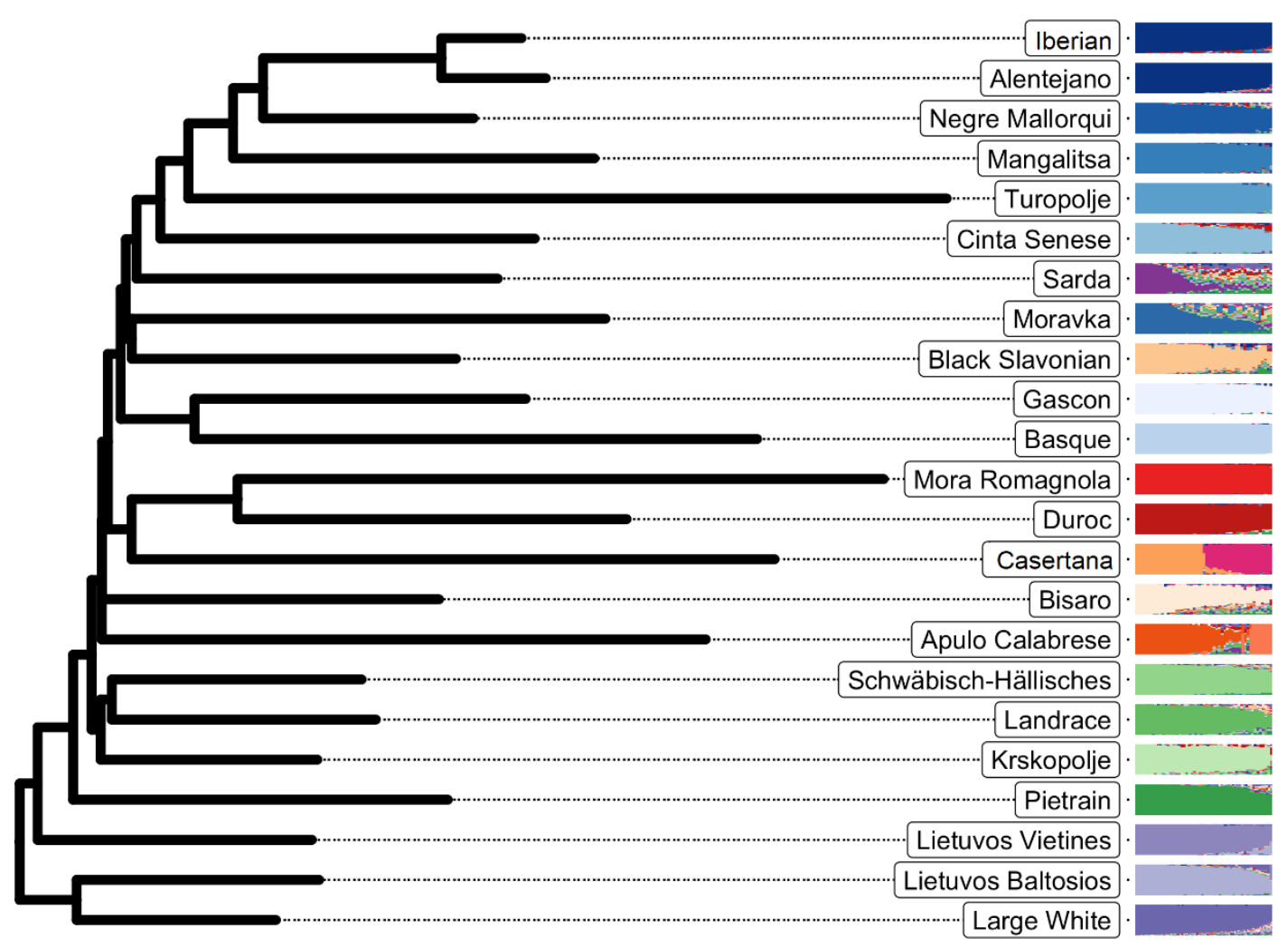

Figure 2. Population tree and admixture analysis of 23 pig breeds genotyped on a medium density SNP array.

The population tree reconstructed from pairwise genetic distances (Fst) is shown on the left, and the admixture component for all individuals a priori belonging to the breed is shown on the right. The colour levels follow the global axes of genetic variation, with populations most closely related to the Iberian type shown in shades of blue, to the Duroc in shades of red, to the Large White in shades of purple, and to the Landrace in shades of green. Heterogeneous populations, or those equidistant from these four clusters, are shown in orange. The Nero Siciliano breed exhibited extremely high heterogeneity, and was therefore not included in the reconstruction of the population tree and is not shown in this figure. 
The population tree is structured consistently with the main axes of variation identified in the PCA analysis with four main genetic backgrounds, highlighted with similar colours in Figure 2. Turopolje and Mora Romagnola breeds differentiated early in the PCA analysis, which could be explained with the population analysis and the fact that they exhibit long branches corresponding to low heterozygosity. This analysis also reveals a general clustering of breeds according to their geographical origin. Breeds closer to the Iberian group mostly originate from the Iberian peninsula or close geographical areas (South West of France with Basque and Gascon breeds, Balearic Islands with Negre Mallorqui breed). Interestingly, some other breeds from different geographical area appear to be related to this background such as Mangalitsa and Moravka from Serbia, the Black Slavonian from Croatia or the Cinta Senese from Italy. Breeds from Central Europe, such as Schwabisch-Hällisches and Krškopolje pig, showed genetic proximity to the Landrace/Pietrain background and breeds from Lithuania in Northern Europe with the Large White component. Finally, some breeds such as the Bísaro from Portugal or Apulo Calabrese from Italy cannot be considered related to any other breed in the dataset.

Sequences from the investigated breeds were aligned to the Sscrofa11.1 reference genome and SNPs were discovered with the pool-seq variant caller CRISP. The detected variants were verified with SNP-chip results, which were published in a previous study of (9).

\section{Phenotypic differentiation of European local pig breeds}

A database of available published results on phenotypic traits of 20 local pig breeds (3) was used in order to distribute local pig populations according to phenotype including stature, growth, fatness traits, and reproductive performance traits. The representation of relationships between breeds and variables was demonstrated by PCA analyses. The first two principal components of the PCA for stature, growth, fatness, and reproduction group accounted for $98.2 \%, 83.2 \%, 84.3 \%$ and $70.7 \%$ of 
the total variance, respectively (Figure 3, Additional File 1: Figures S4, S5, S6). Scores for each breed from PC of all phenotypic groups were extracted from PCA.

The first principal component of the stature group (Figure 3) represented the majority of the total variability (77.3\%) and clearly distributed breeds according to average height and weight. Thus, breeds with lower breed scores for stature (e.g. Moravka, Turopolje, Nero Siciliano, Negre Mallorqui) were smaller and lighter, while breeds with higher breed scores were taller and heavier breeds (e.g. Schwäbisch-Hällisches, Lietuvos Baltosios Senojo Tipo, Krškopolje pig, Lietuvos Vietiné).

The growth group distributed local breeds according to their growth capacity, including data on average daily gain for the rearing period from the lactation period to the early fattening phase (i.e. up to $60 \mathrm{~kg}$ body weight) (Additional File 1: Figure S4). The first PC explained $56.1 \%$ of the total variability and distributed the breeds with the highest (i.e. Schwäbisch-Hällisches, Lietuvos Baltosios Senojo Tipo, Lietuvos Vietiné, Bisaro, Krškopolje pig) and the lowest (i.e. Alentejano, Moravka, Black Slavonian, Mangalitsa and Turopolje) growth potential.

Fatness traits comprised variables associated with the fatty phenotype (Additional File 1: Figure S5). Principal component 1 (59.3\% of total variability) was positively correlated with backfat thicknesses at different anatomical locations and intramuscular fat content. Conversely, lean meat and PUFA content (i.e., lean phenotype) were negatively correlated with PC1. Because intramuscular fat content is a trait of particular interest, the distribution of breeds by intramuscular fat content is shown in Additional File 1: Figure S7. Local breeds were divided into fatter (e.g. Moravka, Iberian, Mangalitsa, Negre Mallorqui) or leaner phenotypes (e.g. Schwäbisch-Hällisches, Lietuvos Baltosios Senojo Tipo, Bisaro). 
A Stature - breeds

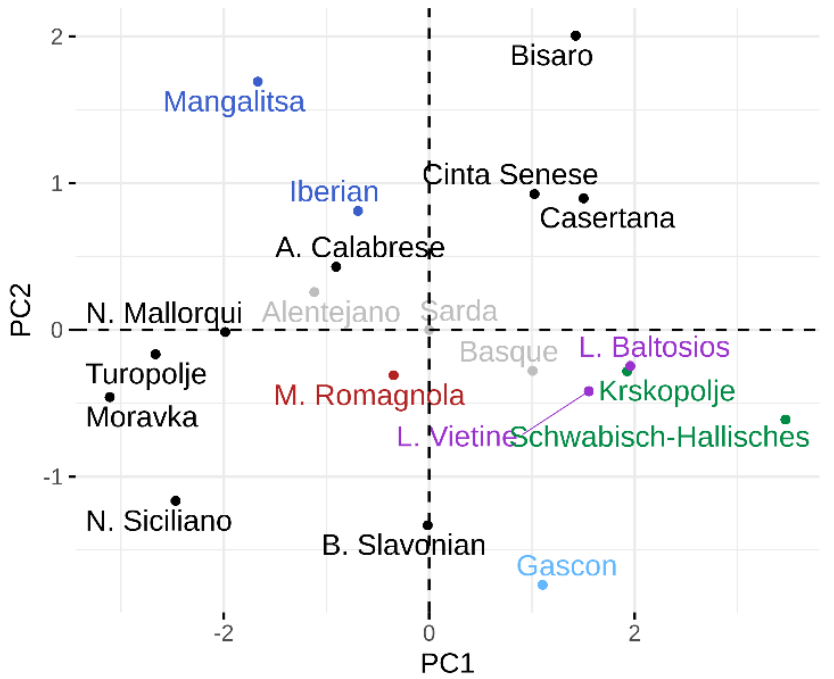

B

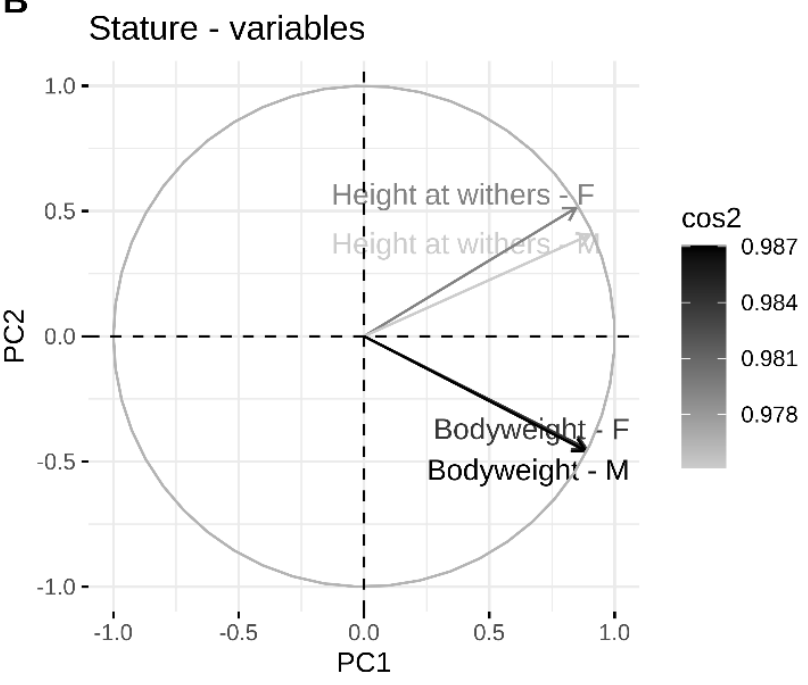

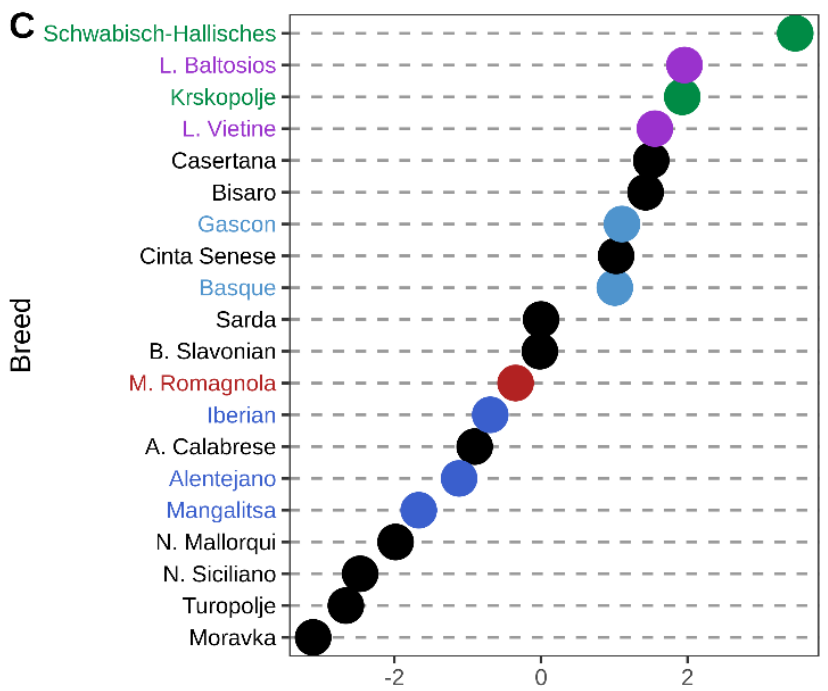

Breed scores for phenotypic group stature

Figure 3. Principal component analysis showing the relationship between breeds (A) and the traits associated with stature (B) and the corresponding phenotypic breed scores (C).

Breeds (A) coloured in grey are the breeds with more than $50 \%$ of missing variables, thus, their position on the PCA must be interpreted carefully. The variables (B) are coloured according to quality of the representation, which is measured by squared cosine between the vector originating from the element and its projection on the axis. The variables that contribute most to the separation of the trait into PC1 and PC2 are coloured black. Breeds (A, C) are coloured according to genetic similarity. Breeds (A, C) in green are genetically Landrace-like breeds, in purple are Large White-like breeds, in blue are Iberian-like breeds, in red are Duroc-like breeds and in light blue are Gascon and Basque.

359 The final characterization of local pig breeds was done according to reproductive performance and piglet birth weights (i.e. Schwäbisch-Hällisches, Lietuvos Baltosios Senojo Tipo, Lietuvos 
Vietiné, Bisaro, Krškopolje pig) from breeds that had lower reproductive performance with smaller

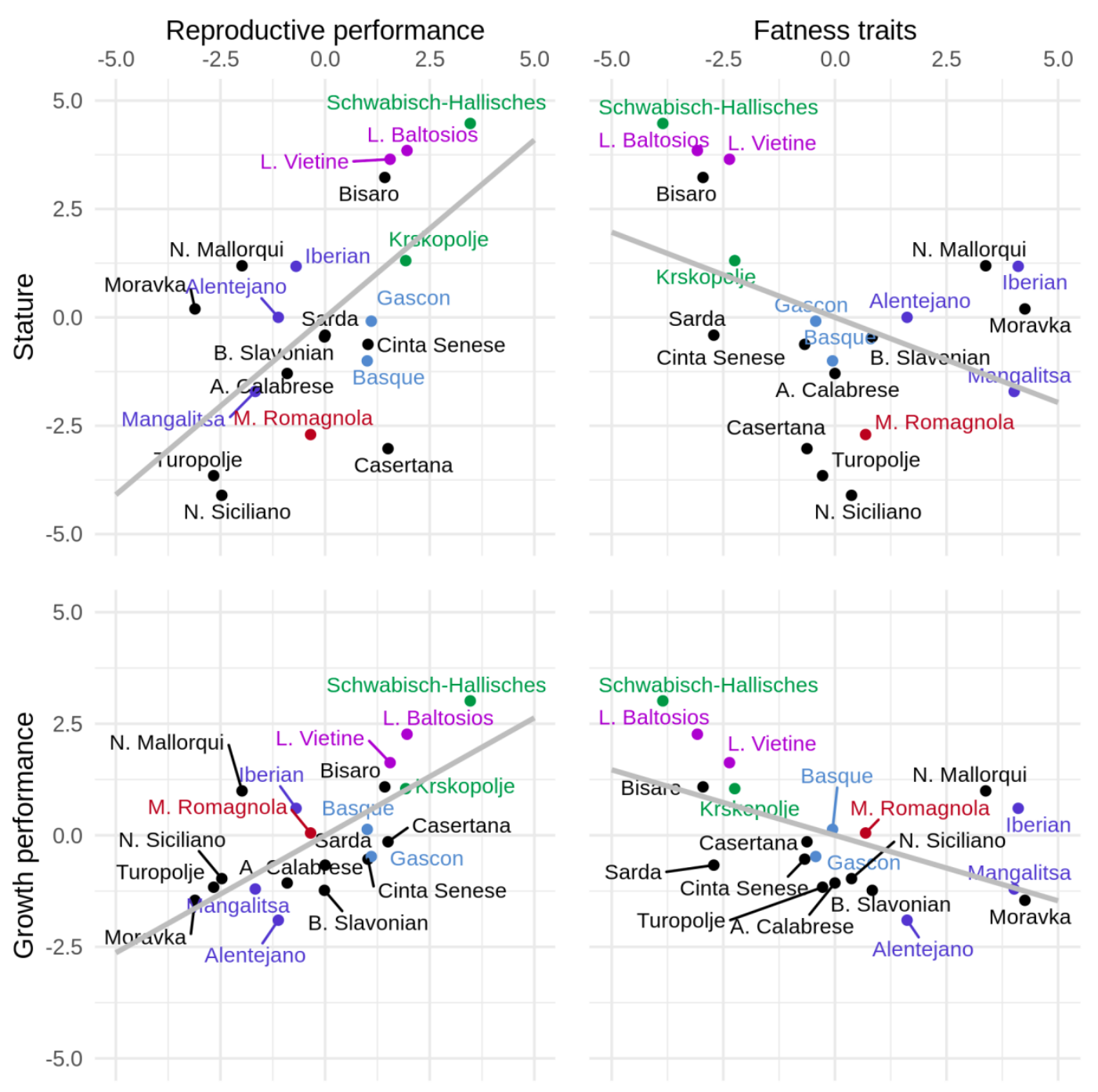


Figure 4. Global differences in production traits for 20 European local pig populations. Breeds are distributed according to breed scores for phenotypic traits and colored according to genetic similarity. Low values for breed score growth are representing lower average daily gain from lactation up to $60 \mathrm{~kg}$ of live weight, while higher values represent higher average daily gain in the same growth period. Low values for breed score reproduction represent low reproductive performance, while high values represent higher reproductive performance of breeds. Low values for breed score stature represent lighter and smaller breeds, while high values represent heavier and larger breeds. Low values for the breed score fat represent leaner breeds, while high values represent fatter breeds. Breeds in green are genetically Landrace-like breeds, in purple are Large White-like breeds, in blue are Iberian-like breeds, in red are Duroc-like breeds and in light blue are Gascon and Basque.

\section{Detection of genomic regions associated with phenotypic differentiation}

In the present study, the approach proposed by Coop et al. (28) was extended to breed-level phenotypes to find genomic regions potentially influencing phenotypic differentiation in local European pig breeds. Therefore, a selection signature scan was performed for each phenotypic breed score, resulting in p-values for each SNP. Figure 5 shows an example of the genome-wide distribution of selection signatures for phenotypic breed score stature.



Figure 5. Manhattan plot for phenotypic group of traits stature with significance threshold 0.01. Each change of color is a new chromosome. Each peak is a possibly under selection region.

The enrichment of significant variants associated with phenotype was tested (Figure 6). The significant SNPs in the phenotypic group fatness were significantly enriched in the intergenic, $5^{\prime}$ prime UTR and coding region. The growth group had significantly enriched SNPs in the 5' prime UTR and the stature group has significantly enriched SNPs in the intronic region. 




395 Figure 6. Enrichment of SNPs associated with different traits into functional categories.

396 Across the genome, windows/regions with at least 3 significant SNPs with less than $200 \mathrm{kbp}$ apart 397 were considered as selection signals for phenotypes. Overall, a total of 561 regions/windows ranging 398 in length from $58 \mathrm{bp}$ to $1.282 \mathrm{Mbp}$ were discovered. Among the detected regions, 51 regions were in 399 the stature group, 47 regions were in the growth group, 221 regions were in the fatness group, and 242 regions were in the reproduction group. For a list of all selection signatures for phenotypes, see Additional File 4.

Within the detected regions in each phenotypic group, the 20 most significant regions were used for 403 interpretation and more detailed description (Figure 7, Additional File 5: Table S1-S4). Regions in 404 the phenotypic group stature contained regions between $1.6 \mathrm{kbp}$ and $565.7 \mathrm{kbp}$ with 3 to $63 \mathrm{SNPs}$ and 405 included from none to five genes. The strongest selection signal for stature was detected on 
chromosome SSC6, which contains the ARHGAP28 gene. The phenotypic group growth contained regions from 6.3 to $709.1 \mathrm{kbp}$ with 3 to 124 significant SNPs and comprised between zero and 20 genes. The region with the strongest selection signal was on SSC18 and did not contain any gene. 409 The phenotypic group fatness contained regions ranging from $3.4 \mathrm{kbp}$ to $980.9 \mathrm{kbp}$ in length with 4 410 to 240 SNPs and included between none and 30 genes. The region with the strongest selection signal 411 was on SSC3 and contained 7 genes, including POMC, DNMT3A, EFR3B, and NCOA1. The 412 phenotypic group reproduction contained regions from $5.3 \mathrm{kbp}$ to $1,282.0 \mathrm{kbp}$ in length with 3 to 115 413 SNPs and zero to 48 genes. The region with the strongest signals was located on chromosome SSC6 414 and contained 4 genes (i.e. YES1, ENOSF1, TYMS, and CLUL1). The detected selection signals for 415 production traits were further examined to find overlaps between groups (Figure 7). In total, there were 12 overlaps. 




Figure 7. Circular plot summarizing top 20 regions with candidate genes with the highest P-value for each phenotypic group. Discovered regions associated with growth are coloured in red, with stature are coloured in blue, with fatness are coloured in purple and with reproductive performance in green.

\section{Discussion}

422 Deciphering the genetic basis of variation in complex traits can help to understand their biology and 423 evolution, and improve breeding, selection programs and conservation plans of animal genetic resources. One approach to address this question is to link genetic and phenotypic variation by 
identifying genomic regions that have evolved in response to selection on complex traits. Establishing such links requires a collection of data on genetic groups (e.g. populations, lines, breeds) that share a common origin and have information on adaptive traits that can be phenotyped in a standardized fashion. Livestock species generally meet these criteria and therefore provide good models for mapping genomic regions associated with selective constraints. Here, we studied local pig populations that were genetically characterized using individual genotyping and pool sequencing for which a recent common phenotypic database was constituted. The genetic relationships between breeds confirmed genome scans for response to selection for a wide range of traits measured as part of their breeding management.

\section{Genetic diversity of European local pig breeds}

Using individual genotyping of a large set of European breeds, we have found that their genetic variation is attracted to four main genetic groups: the Duroc-like, the Large White pigs, the Landrace and the Iberian-like. The origin of the Duroc is unclear, as it originated from American continent and was then brought back to Europe. This history implies that it was separated from the European breeds for a long time, which is evident in our genetic analysis by its rather large genetic distance with most European breeds, except for Mora Romagnola breed from Italy, which has a history of crossbreeding with Duroc breed (32). In addition, the present study showed that Mora Romagnola (and also Turopolje pig breed) differentiated early in the PCA analysis, which can be explained with the high levels of inbreeding (33). The White pig group is composed of the Lietuvos breeds and the Large White, all of which originate from Northern Europe and are clearly separated from the Landrace, which includes populations originating from more central countries such as Germany (Landrace, Schwäbisch-Hällisches), Belgium (Pietrain) and Slovenia (Krškopolje). The Large White and Landrace groups are close to the root of the population tree, which could be explained by the welldocumented influence (34) of Asian pigs on these genetic pools. Finally, the Iberian group includes 
a set of breeds that are quite geographically dispersed; while many of the Iberian-type breeds are found around southwestern Europe (Spain, Portugal, and France), some populations from Eastern/Central Europe clearly belong to the same genetic pool (e.g. Mangalitsa from Serbia, Turopolje from Croatia, Cinta Senese from Italy) as it was already reported in Muñoz et al. (9). A possible interpretation is that the genetic background responsible for variation in the Iberian pig breed was historically widespread in Europe and can still be found in some local pig breeds. Overall, analysis of the genetic structure of European local pig breeds reveals extensive genetic variation clustered in differentiated breeds with continuously distributed genetic distances. The historical events that led to the present genetic variation are most likely complex, and involve differentiation from an ancestral pool followed by or accompanied by outcrossing between populations, including wild boars, and cannot be reconstructed from the data used here. However, the sample of available breeds is well adapted to our main objective, as we can interrogate a diverse set of polymorphisms for adaptation to contrasting environments or production systems in different genetic backgrounds.

While SNP genotyping is sufficient to characterize the genetic relationships and population structure of local pig breeds, the density of the SNP array used limits the resolution and power to detect potential associations with breed phenotypes especially in local breeds where a big proportion of SNPs included in the commercial chips are not segregating. To alleviate this issue, a cost-effective alternative to SNP genotyping consists of pool sequencing of populations. In the dataset used here, we confirmed that allele frequency and genetic structure estimates obtained from pool sequencing are consistent with those obtained from SNP array genotyping as it was already reported in Bovo et al. (8), while providing comprehensive information on the genetic diversity of local pig breeds.

\section{Phenotypic diversity of European local pig breeds}


In parallel with the comprehensive information on the genetic diversity of local pig breeds, we developed an original approach based on PCA to characterize their phenotypic diversity in traits related to stature, growth, fatness and reproduction, which have been described in a comprehensive analysis (3). In addition, local breeds could be phenotypically characterized in regard to meat quality traits $(\mathrm{pH} 24, \mathrm{pH} 48$, intramuscular fat content and longissimus dorsi muscle colour, Additional File S1: Figure S8). However, meat quality traits (with the exception of IMF) are strongly influenced by pre-slaughter handling stress (35). Breed score for meat quality was therefore not included in the phenotype-genotype selection scan.

Local pig breeds exhibit a wide variety of exterior phenotypic characteristics, including body size or body weight. This could be due to genetic factors or could reflect the management of the breed. For example, male and female animals of the Schwäbisch-Hällisches breed are medium to large in size and also have well-developed management systems. In contrast, more untapped breeds (e.g. Moravka) are smaller and lighter (3). Moreover, the distribution of local pig breeds in stature traits was similar to that in the growth performance group.

Regarding the growth performance of local pig breeds, existing knowledge is limited. Moreover, the production systems may not be sufficiently adapted to the needs of the breeds which could be reflected in the phenotype of the breeds. For example, the study of Brossard et al. (36) argues that in many studies on local pig breeds, animals are fed below ad libitum level and, therefore, do not reach their full production potential. This is consistent with an analytical literature review (37) on European local pig breeds, which demonstrated that local pig breeds are generally fed in ad libitum conditions only earlier in life (during the growing and early fattening phase). In the late fattening phase, the feeding is likely to be restricted. To limit the influence of such effects in the present study and to use a better representation of breeds' growth potential, only average daily gain values from the beginning of the 
lactation to the end of the early fattening phase (i.e. up to $60 \mathrm{~kg}$ ) were used for the phenotypic score on growth. Despite this, better growth performance might still partly reflect breeding management, as shown for the Schwäbisch-Hällisches pig, which has a growth potential comparable to genetically improved modern pig breeds $(38,39)$.

It has been reported that local pig breeds have a lower protein and higher lipid deposition capacity compared to modern pig breeds (36). The higher genetic capacity of local pig breeds for backfat and intramuscular fat deposition, and lower muscle accretion has been demonstrated in several studies comparing fat characteristics between local and modern breeds (40-44). Although the local pig breeds are recognised as fatty, they still exhibit large phenotypic variability in the dataset used here.

Regarding reproduction traits, sows of local breeds typically exhibit relatively high age at first parturition, few litters per sow per year, long lactation periods, small litter sizes and high piglet mortality (37). In our study, PCA of reproductive performance distinguished breeds with better reproductive efficiency, which are usually reared in more intensive systems within more developed pork chains (e.g. Schwäbisch-Hällisches pig) from breeds with lower reproductive efficiency (e.g. Nero Siciliano, Turopolje, Casertana, Mora Romagnola, Mangalitsa) reared in extensive or semiextensive systems (3).

While some of this variation in phenotypes can certainly be explained by differences in production systems among local breeds, our genetic association results suggest that some of it may be linked to genetic variation. In order to be able to test for these genetic associations, the methods used require all breeds to have an associated phenotype. To do so, we imputed using PCA the missing phenotypes of some breeds (see Methods). The resulting imputed phenotypes are likely to be biased toward the average of all breeds. This is for example most likely the case for the Sarda breed, considered to be a 
very small breed (in term of body size) but lying at an intermediate value after imputation. This certainly limits our power to detect genetic associations but is unlikely to create false positives.

\section{Genome scan of genomic regions associated with phenotypic differentiation in European local pig breeds}

The functions of some candidate genes identified within the signatures of selection indicated that some local pig breeds may have adapted to specific phenotypic traits such as stature, growth, fatness or reproductive performance. For these regions, it is believed that genetic variations contributed to the development of different phenotypic traits in European local pig breeds. For example, a strong association was found for stature in a region on chromosome SSC3 containing the $A N X A 4$ gene. Annexin A4 encodes a calcium-dependent phospholipid-binding protein involved in various membrane processes. This candidate gene or region has been previously proposed as a QTL for stature in cattle $(45,46)$. Another genomic region associated with the signature of selection for stature and growth was discovered on SSC3 containing also candidate gene ANTXR1. This gene is involved in cell morphogenesis, cellular development process and cytoskeleton organisation. Part of this region has also been previously proposed as a QTL for bovine stature (47). On chromosome SSC8, a region containing the TLL1 gene was found, which encodes a tolloid member of metalloprotease that converts latent to biologically active myostatin, and thus inhibits skeletal muscle development (48). This gene has previously been linked to average daily gain in cattle (49). In the fatness and also stature group, an overlapping region was found on chromosome SSC3. This region contained common candidate genes; namely DNMT3A (responsible for $\mathrm{CpG}$ methylation), POMC (prohormone) and EFR3B (localises phosphatidylinositol 4-kinase to the plasma membrane). DNMT3A has been previously shown to affect stature and body weight in cattle and humans (47,50,51). In addition, the $D N M T 3 A$ gene has previously been implicated to the regulation of adipose tissue development (52). Another candidate gene found in the same region is the POMC gene, which encodes the precursor of 
several peptide hormones that contribute to the regulation of feed intake and energy balance via the leptin/melanocortin pathway (53). Polymorphisms in $P O M C$ have previously been associated with longissimus dorsi muscle area and backfat thickness in cattle (54-56) and with obesity and body mass index in humans $(57,58)$. Additionally, in the fatness group, the NCOA1 gene was detected in the same region on SSC3, which plays an important role in adipogenesis. An interesting signature of selection on reproductive performance was found on chromosome SSC4, which contains the HSD17B7 gene. This gene encodes an enzyme involved in the biosynthesis of sex steroids and cholesterol $(59,60)$. Due to the clear role of the HSD17B7 gene in steroidogenesis, this gene has been proposed as a good candidate gene for reproductive performance in local pig breeds.

Several other regions have also been identified as selection signatures for stature, growth, and fatness with not so direct connection to their biological function in production traits, but still with some association to phenotype. These regions could be useful for further/future studies on selection signatures. For example, chromosome SSC6 contained a region with possible adaptation on stature with the gene $A R H G A P 28$, which has previously been associated with the number of vertebrae in pigs, thus affecting carcass length (61). On chromosome SSC7, a region under adaptation on growth containing the gene PKHD1 has been found, which has been previously associated with carcass conformation score in cattle (62). In the fatness group, the gene EIF2AK1 (located on chromosome SSC3) was identified, with a role of inhibiting of the protein synthesis in response to stress. This gene has previously been associated to body mass index in pigs (63).

Some of regions that have been discovered must be carefully interpreted. For instance, the conducted studies differ in production conditions. Therefore, correlations between phenotypic groups could create non-causal signal with genes. An example of a non-causal signal due to phenotypic correlation found in the growth and fatness groups is a region on SSC8 containing the gene KIT. This gene 
encodes the tyrosine kinase receptor and has been associated with coat colour in pigs. Another selection signature associated with coat colour was found on chromosome SSC6 in the growth and fatness groups. It contains the $M C 1 R$ gene, which plays a major role in controlling the transition from eumelanin (black or brown) to pheomelanin (yellow to red) (64). The same selection signatures (i.e. KIT and MC1R gene) were also observed using the same pool-sequencing data in the study of Bovo et al. (8). Since the coat colour was favoured by breeders, it was strongly selected in several local breeds (65) (e.g. White breeds were under selection for leanness and better growth performance). Interestingly, the study performed on SNP-chip data on the same animals/breeds (9) did not detect any signal near $M C 1 R$ or $K I T$ genes probably due to different SNP-chip informativity and statistical approach used in their study.

\section{Comparison of the detected regions with other studies}

Detected selection signatures were compared with previous study performed on European local pig breeds using the same whole genome re-sequencing data (8). Selection signals in individual breeds, different groups of breeds (i.e. local vs commercial pig breeds and domestic vs wild boar) and on breeds with distinct exterior traits (i.e. coat colour, body size) were searched using Fst approach. The comparison of both approaches revealed few common regions, probably due to the different methodologies applied. For instance, an overlapping region was found on chromosome SSC8 in the stature group containing FRYL gene, which is responsible for maintaining the integrity of polarized cell extensions during morphogenesis. In the fatness group, two overlapping selection signals were detected. The first one on chromosome SSC14 contained RAB11FIP2 gene (found in Alentejano breed) and the second one on chromosome SSC15 contained several candidate genes (e.g., TMEM237, STRADB, MPP4, CASP10). This selection signal was in the study of Bovo et al. (8) detected in two individual breeds (i.e. Casertana and Negre Mallorqui), in the comparison of breeds with small and large body sizes and in the comparison of local and commercial breeds. 
587

588

589

590

591

592

593

594

595

596

597

598

599

600

601

602

603

604

605

606

607

608

609

\section{Conclusions}

In this study, DNA-pool sequencing data of European local pig breeds were used to identify genomic regions associated with phenotypic differences in groups of traits related to stature, growth, fatness and reproductive performance. The genome scan for selection revealed several strong candidate genes with potential implication in adaptation of European local pig breeds to different production systems. This study will be helpful for future conservation, association or selection approaches in these European local pig breeds.

\section{Declarations}

Ethics approval and consent to participate

Not applicable.

\section{Consent for publication}

Not applicable.

\section{Availability of data and materials}

Data used in this study are available from the original sources as detailed in the Materials and Methods section.

\section{Competing interests}

The authors declare that they have no competing interests.

\section{Funding}

This research was funded by the Horizon 2020 Framework Programme, grant number No 634476 and Slovenian Research Agency (grants P4-0133, J4-3094, PhD scholarship for K.P.).

\section{Authors' contributions}

BS, MČP and MŠ conceived the study. MČP and MŠ obtained project funding and were responsible for project administration. BS supervised the study and designed the methodology. CO, LF, SB, GS, 
AR, MM, MG, RB. RC, RQ, GK, MJM, CZ, VR, JPA, ČR, RS, DK provided data and samples. KP, $\mathrm{CM}$, BS performed data analysis. KP, CM, BS, MČP, MŠ, LF, CO and JR contributed to data interpretation. KP, CM and BS wrote the initial draft of the paper. All authors reviewed and edited paper. All authors read and approved the final manuscript.

\section{Acknowledgements}

This study has received funding from the European Union's Horizon 2020 research and innovation programme under grant agreement No 634476 (project acronym TREASURE). Project TREASURE consortium is acknowledged for providing the samples. The content of this paper reflects only the author's view and the European Union Agency is not responsible for any use that may be made of the information it contains. Core financing of the Slovenian Research Agency (grant P4-0133, J4-3094, PhD scholarship for KP) for KP, MČP and MŠ is acknowledged.

\section{References}

1. Tribout T, Caritez JC, Gruand J, Bouffaud M, Guillouet P, Billon Y, et al. Estimation of genetic trends in French Large White pigs from 1977 to 1998 for growth and carcass traits using frozen semen. J Anim Sci. 2010;88(9):2856-67.

2. Rauw WM, Kanis E, Noordhuizen-Stassen EN, Grommers FJ. Undesirable side effects of selection for high production efficiency in farm animals: a review. Livest Prod Sci. 1998;56(1):15-33.

3. Čandek-Potokar M, Nieto R. European Local Pig Breeds - Diversity and performance. A study of project TREASURE. London: Intech Open; 2019. 303 p.

4. Pugliese C, Sirtori F. Quality of meat and meat products produced from southern European pig breeds. Meat Sci. 2012;90(3):511-8.

5. Porter V. Pigs: A Handbook to the breeds of the world. New York: Cornell University Press; 1993. $256 \mathrm{p}$.

6. Ribani A, Utzeri VJ, Geraci C, Tinarelli S, Djan M, Veličković N, et al. Signatures of dedomestication in autochthonous pig breeds and of domestication in wild boar populations from MC1R and NR6A1 allele distribution. Anim Genet. 2019;50(2):166-71.

7. Poklukar K, Čandek-Potokar M, Batorek Lukač N, Tomažin U, Škrlep M. Lipid deposition and metabolism in local and modern pig breeds: A review. Animals. 2020;10(3):424.

8. Bovo S, Ribani A, Muñoz M, Alves E, Araujo JP, Bozzi R, et al. Whole-genome sequencing of European autochthonous and commercial pig breeds allows the detection of signatures of selection for adaptation of genetic resources to different breeding and production systems. Gen Sel Evol. 2020;52(1):33.

9. Muñoz M, Bozzi R, García-Casco J, Núñez Y, Ribani A, Franci O, et al. Genomic diversity, linkage disequilibrium and selection signatures in European local pig breeds assessed with a high density SNP chip. Sci Rep. 2019;9(1):1-14. 
10. Muñoz M, Bozzi R, García F, Núñez Y, Geraci C, Crovetti A, et al. Diversity across major and candidate genes in European local pig breeds. PLOS ONE. 2018 Nov 20;13(11):e0207475.

11. Amaral AJ, Bressan MC, Almeida J, Bettencourt C, Moreira O, Sá J, et al. Combining genome-wide association analyses and gene interaction networks to reveal new genes associated with carcass traits, meat quality and fatty acid profiles in pigs. Livest Sci. 2019;220:180-9.

12. Schiavo G, Bovo S, Tinarelli S, Bertolini F, Dall'Olio S, Gallo M, et al. Genome-wide association analyses for several exterior traits in the autochthonous Casertana pig breed. Livest Sci. 2019;230:103842.

13. Jiang Y, Tang S, Wang C, Wang Y, Qin Y, Wang Y, et al. A genome-wide association study of growth and fatness traits in two pig populations with different genetic backgrounds. J Anim Sci. 2018;96(3):806-16.

14. Wang Y, Ning C, Wang C, Guo J, Wang J, Wu Y. Genome-wide association study for intramuscular fat content in Chinese Lulai black pigs. Asian-Australas J Anim Sci. 2019;32(5):607-13.

15. Strucken EM, Schmitt AO, Bergfeld U, Jurke I, Reissmann M, Brockmann GA. Genomewide study and validation of markers associated with production traits in German Landrace boars. J Anim Sci. 2014;92(5):1939-44.

16. Wilkinson S, Lu ZH, Megens H-J, Archibald AL, Haley C, Jackson IJ, et al. Signatures of Diversifying Selection in European Pig Breeds. PLOS Genet. 2013;9(4):e1003453.

17. Yang S, Li X, Li K, Fan B, Tang Z. A genome-wide scan for signatures of selection in Chinese indigenous and commercial pig breeds. BMC Genet. 2014;15(1):7.

18. Choi J-W, Choi B-H, Lee S-H, Lee S-S, Kim H-C, Yu D, et al. Whole-Genome Resequencing Analysis of Hanwoo and Yanbian Cattle to Identify Genome-Wide SNPs and Signatures of Selection. Mol Cells. 2015;38(5):466-73.

19. Gurgul A, Jasielczuk I, Ropka-Molik K, Semik-Gurgul E, Pawlina-Tyszko K, Szmatoła T, et al. A genome-wide detection of selection signatures in conserved and commercial pig breeds maintained in Poland. BMC Genet. 2018;19:95.

20. Bansal V. A statistical method for the detection of variants from next-generation resequencing of DNA pools. Bioinform. 2010;26(12):i318-24.

21. Alexander DH, Novembre J, Lange K. Fast model-based estimation of ancestry in unrelated individuals. Genome Res. 2009;19(9):1655-64.

22. Li H, Handsaker B, Wysoker A, Fennell T, Ruan J, Homer N, et al. The sequence alignment/map format and SAMtools. Bioinform. 2009;25(16):2078-9.

23. Kofler R, Pandey RV, Schlötterer C. PoPoolation2: identifying differentiation between populations using sequencing of pooled DNA samples (Pool-Seq). Bioinform. 2011;27(24):3435-6. 
24. Hivert V, Leblois R, Petit EJ, Gautier M, Vitalis R. Measuring Genetic Differentiation from Pool-seq Data. Genetics. 2018;210(1):315-30.

25. Josse J, Husson F. missMDA: A Package for Handling Missing Values in Multivariate Data Analysis. Journal of Statistical Software. 2016 Apr 4;70(1):1-31.

26. Lê S, Josse J, Husson F. FactoMineR: An R Package for Multivariate Analysis. J Stat Softw. 2008;25(1):1-18.

27. Josse J, Pagès J, Husson F. Multiple imputation in principal component analysis. Adv Data Anal Classif. 2011;5(3):231-46.

28. Coop G, Witonsky D, Di Rienzo A, Pritchard JK. Using environmental correlations to identify loci underlying local adaptation. Genetics. 2010;185(4):1411-23.

29. Gautier M. Genome-Wide Scan for Adaptive Divergence and Association with PopulationSpecific Covariates. Genetics. 2015;201(4):1555-79.

30. Storey JD, Tibshirani R. Statistical significance for genomewide studies. PNAS. 2003;100(16):9440-5.

31. Gu Z, Gu L, Eils R, Schlesner M, Brors B. circlize implements and enhances circular visualization in R. Bioinform. 2014;30(19):2811-2.

32. Tinarelli S, Ribani A, Utzeri VJ, Taurisano V, Bovo C, Dall'Olio S, et al. Redefinition of the Mora Romagnola Pig Breed Herd Book Standard Based on DNA Markers Useful to Authenticate Its "Mono-Breed" Products: An Example of Sustainable Conservation of a Livestock Genetic Resource. Animals. 2021 Feb;11(2):526.

33. Schiavo G, Bovo S, Muñoz M, Ribani A, Alves E, Araújo JP, et al. Runs of homozygosity provide a genome landscape picture of inbreeding and genetic history of European autochthonous and commercial pig breeds. Animal Genetics. 2021;52(2):155-70.

34. Frantz LAF, Schraiber JG, Madsen O, Megens H-J, Cagan A, Bosse M, et al. Evidence of long-term gene flow and selection during domestication from analyses of Eurasian wild and domestic pig genomes. Nat Genet. 2015;47(10):1141-8.

35. Dokmanovic M, Baltic MZ, Duric J, Ivanovic J, Popovic L, Todorovic M, et al. Correlations among stress parameters, meat and carcass quality parameters in pigs. Asian-Australas J Anim Sci. 2015;28(3):435-41.

36. Brossard L, Nieto R, Charneca R, Araujo JP, Pugliese C, Radović Č, et al. Modelling nutritional requirements of growing pigs from local breeds using InraPorc. Animals. 2019;9(4):169.

37. Čandek-Potokar M, Batorek-Lukač N, Tomažin U, Škrlep M, Nieto R. Analytical review of productive performance of local pig breeds. In: European local pig breeds - diversity and Performance A study of project TREASURE. London: Intech Open; 2019. p. 281-303. 
38. Petig M, Zimmer C, Bühler R, Batorek-Lukač N. Schwäbisch-Hällisches Pig. In: European local pig breeds - diversity and performance A study of project TREASURE. London: Intech Open; 2019. p. 258-66.

39. Bozzi R, Škrlep M, Lenoir H, Lebret B, Gasco G, Petig M, et al. Survey of demographic and phenotypic data of local pig breeds of TREASURE project. In: Archivos de Zootecnia. 2018. p. 4.

40. Serra X, Gil F, Perez-Enciso M, Oliver MA, Vazquez JM, Gispert M, et al. A comparison of carcass, meat quality and histochemical characteristics of Iberian (Guadyerbas line) and Landrace pigs. Livest Prod Sci. 1998;56(3):215-23.

41. Lebret B, Dourmad JY, Mourot J, Pollet PY, Gondret F. Production performance, carcass composition, and adipose tissue traits of heavy pigs: influence of breed and production system. J Anim Sci. 2014;92(8):3543-56.

42. Madeira MS, Pires VMR, Alfaia CM, Costa ASH, Luxton R, Doran O, et al. Differential effects of reduced protein diets on fatty acid composition and gene expression in muscle and subcutaneous adipose tissue of Alentejana purebred and Large White $\times$ Landrace $\times$ Pietrain crossbred pigs. Br J Nutri. 2013;110(2):216-29.

43. Palma-Granados P, Haro A, Seiquer I, Lara L, Aguilera JF, Nieto R. Similar effects of lysine deficiency in muscle biochemical characteristics of fatty and lean piglets. J Anim Sci. 2017;95(7):3025-36.

44. Parunović N, Petrović M, Matekalo-Sverak V, Radović Č, Stanišić N. Carcass properties, chemical content and fatty acid composition of the musculus longissimus of different pig genotypes. S Afr j anim sci. 2013;43(2):123-36.

45. Kolbehdari D, Wang Z, Grant JR, Murdoch B, Prasad A, Xiu Z, et al. A whole-genome scan to map quantitative trait loci for conformation and functional traits in Canadian Holstein bulls. $\mathrm{J}$ Dairy Sci. 2008;91(7):2844-56.

46. Cole JB, Wiggans GR, Ma L, Sonstegard TS, Lawlor TJ, Crooker BA, et al. Genome-wide association analysis of thirty one production, health, reproduction and body conformation traits in contemporary U.S. Holstein cows. BMC Genom. 2011;12(1):408.

47. Bouwman AC, Daetwyler HD, Chamberlain AJ, Ponce CH, Sargolzaei M, Schenkel FS, et al. Meta-analysis of genome-wide association studies for cattle stature identifies common genes that regulate body size in mammals. Nat Genet. 2018;50(3):362-7.

48. Kostyunina DS, Ivanova AD, Smirnova OV. Myostatin: Twenty Years Later. Hum Physiol. 20;44(1):88-101.

49. Higgins MG, Fitzsimons C, McClure MC, McKenna C, Conroy S, Kenny DA, et al. GWAS and eQTL analysis identifies a SNP associated with both residual feed intake and GFRA2 expression in beef cattle. Sci Rep. 2018;8(1):1-12. 
50. Wood AR, Esko T, Yang J, Vedantam S, Pers TH, Gustafsson S, et al. Defining the role of common variation in the genomic and biological architecture of adult human height. Nat Genet. 2014;46(11):1173-86.

51. Liu X, Usman T, Wang Y, Wang Z, Xu X, Wu M, et al. Polymorphisms in epigenetic and meat quality related genes in fourteen cattle breeds and association with beef quality and carcass traits. Asian Australas J Anim Sci. 2015;28(4):467-75.

52. Ma X, Kang S. Functional implications of DNA methylation in adipose biology. Diabetes. 2019;68(5):871-8.

53. Switonski M, Stachowiak M, Cieslak J, Bartz M, Grzes M. Genetics of fat tissue accumulation in pigs: a comparative approach. J Appl Genet. 2010;51(2):153-68.

54. Gill JL, Bishop SC, McCorquodale C, Williams JL, Wiener P. Associations between single nucleotide polymorphisms in multiple candidate genes and carcass and meat quality traits in a commercial Angus-cross population. Meat Sci. 2010;86(4):985-93.

55. Seong J, Kong HS. Association between polymorphisms of the CRH and POMC genes with economic traits in Korean cattle (Hanwoo). Genet Mol Res. 2015;14(3):10415-21.

56. Liu Y, Zan L, Li L, Xin Y. Proopiomelanocortin gene polymorphisms and its association with meat quality traits by ultrasound measurement in Chinese cattle. Gene. 2013;529(1):138-43.

57. Singh RK, Kumar P, Mahalingam K. Molecular genetics of human obesity: A comprehensive review. Comptes Rendus Biologies. 2017;340(2):87-108.

58. Harno E, Gali Ramamoorthy T, Coll AP, White A. POMC: The physiological power of hormone processing. Physiol Rev. 2018;98(4):2381-430.

59. LaVoie HA. Transcriptional control of genes mediating ovarian follicular growth, differentiation, and steroidogenesis in pigs. Mol Reprod Dev. 2017;84(9):788-801.

60. Robic A, Feve K, Louveau I, Riquet J, Prunier A. Exploration of steroidogenesis-related genes in testes, ovaries, adrenals, liver and adipose tissue in pigs. Anim Sci J. 2016;87(8):1041-7.

61. Rohrer GA, Nonneman DJ, Wiedmann RT, Schneider JF. A study of vertebra number in pigs confirms the association of vertnin and reveals additional QTL. BMC Genet. 2015;16(1):129.

62. Mao X, Sahana G, De Koning D-J, Guldbrandtsen B. Genome-wide association studies of growth traits in three dairy cattle breeds using whole-genome sequence data. J Anim Sci. 2016;94(4):1426-37.

63. Gong H, Xiao S, Li W, Huang T, Huang X, Yan G, et al. Unravelling the genetic loci for growth and carcass traits in Chinese Bamaxiang pigs based on a 1.4 million SNP array. J Anim Breed Genet. 2019;136(1):3-14.

64. Kijas JMH, Wales R, Törnsten A, Chardon P, Moller M, Andersson L. Melanocortin receptor 1 (MC1R) mutations and coat color in pigs. Genetics. 1998;150(3):1177-85. 
bioRxiv preprint doi: https://doi.org/10.1101/2022.02.22.481248; this version posted February $22,2022$. The copyright holder for this

preprint (which was not certified by peer review) is the author/funder, who has granted bioRxiv a license to display the preprint in perpetuity. It is made available under aCC-BY-ND 4.0 International license.

65. Groenen MAM. A decade of pig genome sequencing: a window on pig domestication and evolution. Genet Sel Evol. 2016;48(1):23.

791 


\section{Figures}

Figure 1 Principal component analysis of 24 pig breeds genotyped on a medium density SNP array.

The most differentiated breeds are highlighted with different colours.

Figure 2. Population tree and admixture analysis of 23 pig breeds genotyped on a medium density SNP array.

The population tree reconstructed from pairwise genetic distances (Fst) is shown on the left, and the admixture component for all individuals a priori belonging to the breed is shown on the right. The colour levels follow the global axes of genetic variation, with populations most closely related to the Iberian type shown in shades of blue, to the Duroc in shades of red, to the Large White in shades of purple, and to the Landrace in shades of green. Heterogeneous populations, or those equidistant from these four clusters, are shown in orange. The Nero Siciliano breed exhibited extremely high heterogeneity, and was therefore not included in the reconstruction of the population tree and is not shown in this figure.

Figure 3. Principal component analysis showing the relationship between breeds (A) and the traits associated with stature (B) and the corresponding phenotypic breed scores (C).

Breeds (A) coloured in grey are the breeds with more than $50 \%$ of missing variables, thus, their position on the PCA must be interpreted carefully. The variables (B) are coloured according to quality of the representation, which is measured by squared cosine between the vector originating from the element and its projection on the axis. The variables that contribute most to the separation of the trait into PC1 and PC2 are coloured black. Breeds (A, C) are coloured according to genetic similarity. Breeds (A, C) in green are genetically Landrace-like breeds, in purple are Large White-like breeds, in blue are Iberian-like breeds, in red are Duroc-like breeds and in light blue are Gascon and Basque.

Figure 4. Global differences in production traits for 20 European local pig populations.

Breeds are distributed according to breed scores for phenotypic traits and colored according to genetic similarity. Lower values for breed score growth are representing lower average daily gain from lactation up to $60 \mathrm{~kg}$ of live weight, while higher values represent higher average daily gain in the same growth period. Low values for breed score reproduction represent low reproductive performance, while high values represent higher reproductive performance of breeds. Low values for breed score stature represent lighter and smaller breeds, while high values represent heavier and larger breeds. Low values for the breed score fat represent leaner breeds, while high values represent fatter breeds. Breeds in green are genetically Landrace-like breeds, in purple are Large White-like breeds, in blue are Iberian-like breeds, in red are Duroc-like breeds and in light blue are Gascon and Basque.

Figure 5. Manhattan plot for phenotypic group of traits stature with significance threshold 0.01 . 
bioRxiv preprint doi: https://doi.org/10.1101/2022.02.22.481248; this version posted February 22, 2022. The copyright holder for this

preprint (which was not certified by peer review) is the author/funder, who has granted bioRxiv a license to display the preprint in perpetuity. It is made available under aCC-BY-ND 4.0 International license.

828 Each change of color is a new chromosome. Each peak is a possibly under selection region.

829 Figure 6. Enrichment of SNPs associated with different traits into functional categories.

Figure 7. Circular plot summarizing top 20 regions with candidate genes with the highest $P$ 831 value for each phenotypic group.

832 Discovered regions associated with growth are coloured in red, with stature are coloured in blue, with 833 fatness are coloured in purple and with reproductive performance in green. 
835

\section{Additional files}

\section{Additional file 1 Figure S1}

Title: Plot od admixture cross-validation error from $K=2$ to $K=40$.

\section{Additional file 1 Figure S2}

Title: Principal component analysis of pool-sequencing SNPs extracted from SNP-chip data.

\section{Additional file 1 Figure S3}

Title: A matrix of missing phenotypic variables in a database of European local pig breeds. The yellow colour is representing missing variables.

Description: SFA = saturated fatty acid content, PUFA = polyunsaturated fatty acid content, Piglets $\mathrm{W}$ weight $=$ piglets weaning weight, $\mathrm{MUFA}=$ monounsaturated fatty acid content, Litter $\mathrm{W}$ birth $=$ litter weaning weight, $\mathrm{LD}$ IMF = longissimus dorsi intramuscular fat content, $\mathrm{M}=$ male, $\mathrm{F}=$ female, Death $\mathrm{WN}=$ death rate to weaning, $\mathrm{BFT}=$ backfat thickness, $\mathrm{GM}=$ gluteus medius muscle, ADG1 $=$ Average daily gain during the lactation period, $\mathrm{ADG} 2=$ Average daily gain in the growing period from weaning to $30 \mathrm{~kg}$ of weight, $\mathrm{ADG} 3$ = Average daily gain during fattening period from $30 \mathrm{~kg}$ to $60 \mathrm{~kg}$.

\section{Additional file 1 Figure S4}

Title: Principal component analysis showing the relationship between breeds (A) and the traits associated with growth (B) and the corresponding phenotypic breed scores (C).

Description: Breeds (A) coloured in grey are the breeds with more than $50 \%$ of missing variables, thus, their position on the PCA must be interpreted carefully. The variables (B) are coloured according to quality of the representation, which is measured by squared cosine between the vector originating from the element and its projection on the axis. The variables that contribute most to the separation of the trait into PC1 and PC2 are coloured black. Breeds (A, C) are coloured according to genetic similarity. Breeds (A, C) in green are genetically Landrace-like breeds, in purple are Large Whitelike breeds, in blue are Iberian-like breeds, in red are Duroc-like breeds and in light blue are Gascon and Basque.

\section{Additional file 1 Figure S5}

Title: Principal component analysis showing the relationship between breeds (A) and the traits associated with fatness (B) and the corresponding phenotypic breed scores (C).

Description: Breeds (A) coloured in grey are the breeds with more than $50 \%$ of missing variables, thus, their position on the PCA must be interpreted carefully. The variables (B) are coloured according to quality of the representation, which is measured by squared cosine between the vector originating 
from the element and its projection on the axis. The variables that contribute most to the separation of the trait into PC1 and PC2 are coloured black. Breeds (A, C) are coloured according to genetic similarity. Breeds (A, C) in green are genetically Landrace-like breeds, in purple are Large Whitelike breeds, in blue are Iberian-like breeds, in red are Duroc-like breeds and in light blue are Gascon and Basque.

\section{Additional file 1 Figure S6}

Title: Principal component analysis showing the relationship between breeds (A) and the traits associated with reproduction performance (B) and the corresponding phenotypic breed scores (C).

Description: Breeds (A) coloured in grey are the breeds with more than $50 \%$ of missing variables, thus, their position on the PCA must be interpreted carefully. The variables (B) are coloured according to quality of the representation, which is measured by squared cosine between the vector originating from the element and its projection on the axis. The variables that contribute most to the separation of the trait into PC1 and PC2 are coloured black. Breeds (A, C) are coloured according to genetic similarity. Breeds (A, C) in green are genetically Landrace-like breeds, in purple are Large Whitelike breeds, in blue are Iberian-like breeds, in red are Duroc-like breeds and in light blue are Gascon and Basque.

\section{Additional file 1 Figure S7}

Title: Distribution of the European local pig breeds according to intramuscular fat content in longissimus dorsi (LD) muscle.

Description: Higher values on $\mathrm{x}$-axis are representing higher intramuscular fat content, while the lower values are representing lower intramuscular fat content.

\section{Additional file 1 Figure S8}

Title: Principal component analysis showing the relationship between breeds (A) and the traits associated with meat quality (B) and the corresponding phenotypic breed scores (C).

Description: Breeds (A) coloured in grey are the breeds with more than $50 \%$ of missing variables, thus, their position on the PCA must be interpreted carefully. The variables (B) are coloured according to quality of the representation, which is measured by squared cosine between the vector originating from the element and its projection on the axis. The variables that contribute most to the separation of the trait into PC1 and PC2 are coloured black. Breeds (A, C) are coloured according to genetic similarity. Breeds (A, C) in green are genetically Landrace-like breeds, in purple are Large Whitelike breeds, in blue are Iberian-like breeds, in red are Duroc-like breeds and in light blue are Gascon and Basque.

\section{Additional file 2}

Title: Description of the statistical analysis used for adjustment of backfat thickness at the level of the last rib to final body weight of $120 \mathrm{~kg}$. 
903

904

905

906

907

908

909

910

911

912 Format: xls

913

914

915

916

917

918

919

920

921 breeds. pig breeds.

\section{Additional file 3 Table 1}

Title: Description of phenotypic traits used for phenotypic characterisation of European local pig

\section{Additional file 3 Table 2}

Title: Number of significant variants with corresponding q-values at the $1 \%$ level of false discovery rate for phenotypic covariables.

\section{Additional file 4}

Title: A list of detected genomic regions associated with phenotypic differentiation in production traits in European local pig breeds.

\section{Additional file 5 Table S1}

Title: Best 20 significant regions under adaptation on stature in European local pig breeds.

\section{Additional file 5 Table S2}

Title: Best 20 significant regions under adaptation on growth in European local pig breeds.

\section{Additional file 5 Table S3}

Title: Best 20 significant regions under adaptation on fatness in 20 European local pig breeds.

\section{Additional file 5 Table S4}

Title: Best 20 significant regions under adaptation on reproductive performance in 20 European local 